\title{
What drives learner errors in written L2 production?
}

\author{
Surface Overlap versus Derivational Complexity in the English Genitive Alternation \\ 플. UNIVERSITY OF \\ CAMBRIDGE \\ James Algie, ja600@cam.ac.uk \\ Theoretical and Applied Linguistics
}

\section{B A C K GR O U N D}

The English Genitive Alternation refers to the variation in the expression of relationships between two noun phrases in either in the s-genitive (the company's future) or the of-genitive (the future of the company). It typically denotes a possessive relationship. Though this alternation is not unique to English, many other languages are more restrictive in the linear order of the noun phrases.

Spanish (head-initial)

$n / a$

el futuro de la empresa
English (head-initial)

the company's future

the future of the company
Japanese (head-final) kaisha no mirai 会社の未来

$n / a$
The above crosslinguistic variation is a classic example of surface overlap, where Language A (here, Spanish or Japanese) allows one option and Language B (English) allows two. One of the two options in Language B corresponds to the form found in Language A.

The Surface Overlap Hypothesis broadly predicts that, where overlap exists, crosslinguistic influence would lead to a tendency for learners to favour the structure available in their L1 (Hulk \& Müller 2000). The competing hypotheses here were developed in the context of L1 bilingual and monolingual acquisition
In terms of their respective derivational complexity, the sgenitive is more complex than the of-genitive. In order to assign genitive case, the s-genitive requires the raising of the possessum (the company, in the above example) to the specifier of the DP, while the of-genitive requires no such raising as the preposition assigns case (Hawkins 2001: 243244).

The Derivational Complexity Hypothesis predicts that when faced with two structural options, the less complex one (here, the of-genitive) would be favoured. Some evidence suggests that in L2 acquisition, less complex structures appear earlier (Jakubowicz 2005).

\section{RESEARCH QUESTIONS \& METHODS}

- What happens when L2 learners are faced with this 'new' optionality, with only one of the structures available in the L1?

- How and to what extent are usage and accuracy influenced by crosslinguistic influence (i.e. surface overlap) and derivational complexity?

- Cambridge Learner Corpus

- 1,639 written L2 English exam scripts (740k words)

- L1 Japanese and L1 Spanish speakers at A2-C2 levels

- All attempted s-genitives and of-genitives manually categorised according to: genitive type ('s/of); success (correct/incorrect); possessor number (singular, (ir)regular plural)

\begin{tabular}{|c|c|c|c|c|c|c|c|}
\hline $\begin{array}{l}\text { No. of } \\
\text { words }\end{array}$ & A1 & A2 & B1 & B2 & C1 & C2 & Total \\
\hline L1 Japanese & - & 1,182 & 7,755 & 164,977 & 110,674 & 85,933 & 370,521 \\
\hline L1 Spanish & - & 1,283 & 8,128 & 131,250 & 93,638 & 135,215 & 369,514 \\
\hline Total & - & 2,465 & 15,883 & 296,227 & 204,312 & 221,148 & 740,035 \\
\hline
\end{tabular}

\section{RESULTSAND DISCUSSION}

\section{Accuracy - prenominal ('s) contexts \\ Target-like usage (TLU) score}
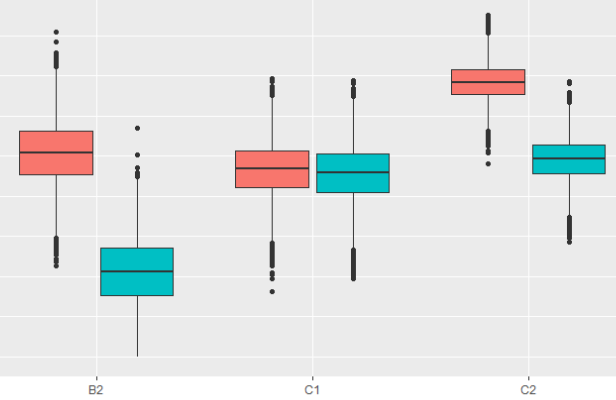

Fig. 1

Proficiency (CEFR level)$$
\text { c2 }
$$

- Frequency of both s- and of-genitives increase with proficiency but the collinear variable of document length may be partly responsible, allowing for greater 'opportunity of use' (Buttery et al. 2012)

- All learners are frequently attempting both genitive types by B1 level (at latest)

- Accuracy rates (TLU; Pica 1983) are consistently higher for of-genitives than s-genitives, indicating support for Derivational Complexity Hypothesis (Fig. 1 vs. Fig. 2)

- L1 effects present in s-genitive contexts at B2 and C2, indicating some influence of surface overlap (Fig. 1)

- Effects of both complexity and crosslinguistic influence appear to be exacerbated by the increased complexity of the plural feature (Fig. 3)
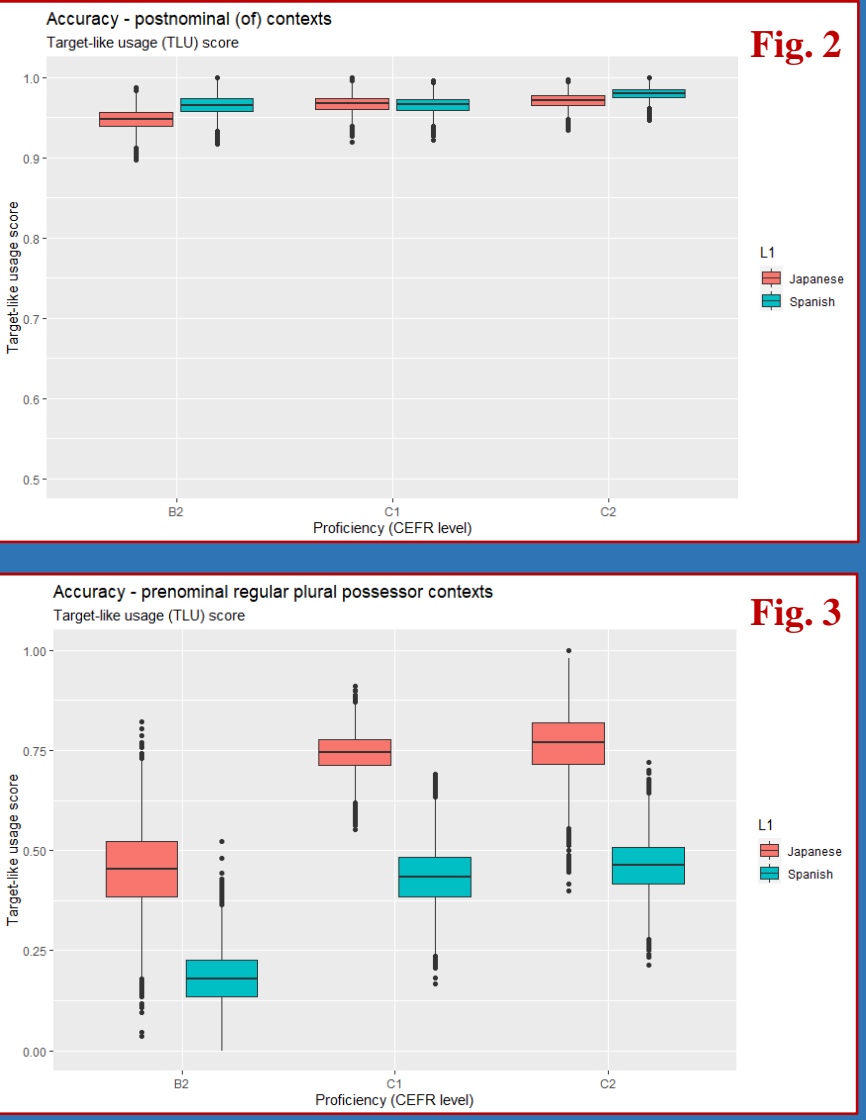